\title{
Highly Effective Adsorption of Caffeine by a Novel Activated Carbon Prepared From Coconut Leaf
}

\section{Elvio N. Oliveira}

Federal University of Alagoas: Universidade Federal de Alagoas

\section{Alex T. Meneses}

Federal University of Alagoas: Universidade Federal de Alagoas

\section{Samara F. de Melo}

Federal University of Alagoas: Universidade Federal de Alagoas

Franciele M. R. Dias

Federal University of Alagoas: Universidade Federal de Alagoas

\section{Maisa T. B. Perazzini}

Federal University of Itajubá: Universidade Federal de Itajuba

\section{Hugo Perazzini}

Federal University of Itajubá: Universidade Federal de Itajuba

\section{Lucas Meili}

Universidade Federal de Alagoas https://orcid.org/0000-0002-0307-8204

\section{João I. Soletti}

Federal University of Alagoas: Universidade Federal de Alagoas

\section{Sandra H. V. Carvalho}

Federal University of Alagoas: Universidade Federal de Alagoas

Mozart D. Bispo ( $\square$ mozartdaltro@hotmail.com )

Federal University of Alagoas: Universidade Federal de Alagoas

\section{Research Article}

Keywords: adsorbent, biochar, carbon, emerging pollutants, kinetic study, surface area

Posted Date: October 27th, 2021

DOl: https://doi.org/10.21203/rs.3.rs-901559/v1

License: (9) This work is licensed under a Creative Commons Attribution 4.0 International License. Read Full License 


\section{Highly effective adsorption of caffeine by a novel activated carbon prepared from}

coconut leaf

\section{Elvio N. Oliveira ${ }^{1}$, Alex T. Meneses ${ }^{1}$, Samara F. de Melo ${ }^{1}$, Franciele M. R. Dias ${ }^{1}$, Maisa T.}

B. Perazzini ${ }^{2}$, Hugo Perazzini ${ }^{2}$, Lucas Meili ${ }^{3}$, João I. Soletti ${ }^{1}$, Sandra H. V. Carvalho ${ }^{1}$, Mozart D. Bispo ${ }^{1 *}$

${ }^{1}$ Laboratory of Separation Systems and Process Optimization (LASSOP), Center of Technology, Federal University of Alagoas (UFAL), Maceió, Alagoas, Brazil ${ }^{2}$ Institute of Natural Resources, Federal University of Itajubá-UNIFEI, Itajubá, MG, Brazil ${ }^{3}$ Laboratory of Processes (LAPRO), Center of Technology, Federal University of Alagoas (UFAL), Maceió, Alagoas, Brazil

\section{*Corresponding author:}

Mozart D. Bispo, Dr.; email: mozartdaltro@hotmail.com; Laboratory of Separation Systems and Process Optimization (LASSOP), Center of Technology, Federal University of Alagoas (UFAL), Maceió, Alagoas, Brazil

Abstract: The disposal of coconut wastes is costly and damaging to the environment, but its uses are advantageous activated carbons production. Coconut leaves waste were used for activated carbon production by pyrolysis at $500^{\circ} \mathrm{C}$ and activation with potassium carbonate. The activated carbon was used for caffeine removal from aqueous solution. The coconut leaves activated carbon showed a predominantly amorphous structure from X-ray diffraction analysis and a $\mathrm{pH}$ at the zero charge point of 7.9. From the $\mathrm{N}_{2}$ adsorption/desorption method, the adsorbent showed a predominance of mesopores, with average pore size of $45.48 \eta \mathrm{m}$ and a 
26 surface area of $678.03 \mathrm{~m}^{2} / \mathrm{g}$. From kinetic studies the data followed the pseudo-second order,

27 where the intraparticle diffusion can be neglected. The adsorption isotherms were satisfactorily

28 adjusted for the Redlich-Peterson model and a type curve $L$ was identified. The thermodynamic

29 parameters showed that adsorption occurred spontaneously, was exothermic and governed by

30 physical adsorption. The artificial neural networks developed were capable of predicting both

31 kinetics and equilibrium adsorption data under different operating conditions and was

32 comparable to the traditional models available in literature in the training experiments,

33 encouraging its use for data generalization when an efficient dataset is used. In conclusion,

34 coconut leaves waste showed to be a promising feedstock to produce activated carbon aiming

35 caffeine removal from water and wastewater.

36

37 Keywords: adsorbent; biochar; carbon; emerging pollutants; kinetic study; surface area 


\section{Introduction}

Coconut is a culture with several uses in people's daily lives and can be processed to obtain a wide variety of value-added products. Coconut grows in more than 97 countries on most continents, Asia, Africa and America[1]. In 2019, the coconut harvested area was 11,807,156 hectares, producing 62,455,08 tons. Indonesia is the world's largest producer of coconut, followed by the Philippines and India. Brazil is the $5^{\text {th }}$ largest coconut producer in the world with 2,330,949 tons [2]. The coconut wastes (shells, leaves and bunches) discarding is both costly and harmful to the environment and its structure, high carbon content and very low ash content are beneficial to synthesize activated carbons [3].

Activated carbons are currently used as an adsorbent in different industries as food, pharmaceutical, chemical, oil, nuclear, automotive and the treatment of water and wastewater [4]. Efficiency and promising operation are the highlight of adsorption technique. This process has great technological maturity and is superior in terms of initial costs, flexibility and simplicity in projects, high efficiency, even at low concentration of pollutants[5,6]. Adsorption methods are already well known, and the literature is full of studies focused on the phenomenological analysis of the process. However, due to the large application of adsorption technology, the search for new and unexplored adsorbents, as well, synthesis routes adsorbents, the precise adjustment of the operating parameters for a low cost preparation, and the effective removal of specific contaminants are still subjects that attract the interest of researchers around the world[7].

In recent years, a new class of contaminants called emerging pollutants (EP) have caused great attention in scientific community. EP are resistant to conventional treatments, toxic and bio-accumulative and they are not comprised in schedules for monitoring water quality and are harmful to the environment and to humans. Their effects and comportment in the environment still demand studies[8,9]. These pollutants are not fully removed in 
64

65

66

67

68

69

70

71

72

wastewater treatment units and drinking water stations because of their high complexity, low concentration and the presence of other compounds that can compete or work as inhibitors $[9,10]$.

Thus, several systems have been studied for the removal of EP [11]. Though, adsorption has been attracting the notice of various researchers due to the high efficiency and low cost [12]. Amid emerging pollutants the caffeine is considered a chemical indicator for surface water pollution because its regular consumption [13]. Caffeine is an alkaloid used as a respiratory stimulant, as an additive in medications to increase analgesic effect and also as an appetite regulator. In addition to the natural occurrence of caffeine it can be found in several widely consumed products such as coffee, chocolate, tea, etc. [14].

In the present work, we propose for the first time the production of the activated carbon from the coconut leaves to evaluate its potential for caffeine (CFN) removal from aqueous solution. For this purpose, the activated carbon was obtained by vacuum pyrolysis $\left(500^{\circ} \mathrm{C}\right)$ and chemically activated with potassium carbonate $\left(\mathrm{K}_{2} \mathrm{CO}_{3}\right)$. The raw materials were characterized by thermogravimetric analysis (TGA) and the activated carbon by $\mathrm{N}_{2}$ adsorption/desorption analysis, X-ray diffraction (XRD), the $\mathrm{pH}$ at the point of zero charge (pHpzc). In order to explore the potentiality of the adsorbent to remove caffeine from aqueous solution adsorption kinetic assessments were carried out and the data were evaluated using pseudo-first order, pseudo-second order and intraparticle diffusion models. The effect of temperature was studied in the range $30-50^{\circ} \mathrm{C}$ and for the better understanding of adsorption phenomenon the Langmuir, Freundlich, Sips and Redlich-Peterson models were fitted to the equilibrium data. The thermodynamics study was conducted to comprehensive the analysis of adsorption mechanism. And to complete the study proposed in this work, artificial neural networks were developed to compare with the conventional models used to foresee kinetic and adsorption equilibrium data. 
2 Materials and Methods

91

92

93

94

97

98

\subsection{Chemicals}

Potassium carbonate $\left(\mathrm{K}_{2} \mathrm{CO}_{3}, 85 \%\right)$ and caffeine (purity $\left.\geq 99 \%\right)$ were purchased from

Sigma-Aldrich. All other chemicals presented analytical grade. CFN has a molecular weight of 194.19 g.mol ${ }^{-1}$ and a pKa of 8.30, which means it is a weak base [15]. Furthermore, CFN has high water solubility (Ks $>10,000 \mathrm{mg} \cdot \mathrm{L}^{-1}$ ), so that hinders its removal in common water and wastewater treatment processes [16].

\subsection{Raw material}

The coconut leaves (CL) were collected in the city of São Miguel dos Milagres, Alagoas, Brazil, at latitude $9^{\circ} 14^{\prime}$ '17.4" South and longitude $35^{\circ} 21$ '16.3" West. The leaves were removed at different stages of life. The CL were cut into pieces and dried in an oven (Fanem, Orion 515, São Paulo, Brazil) at $100^{\circ} \mathrm{C}$ for 24 h [17-19]. The proximate analysis was carried out in triplicate according to the standard methodology from American Society for Testing and Materials (ASTM)-D1762-1984 [20]. The dried sample was analyzed by thermogravimetric (TG) and derivative thermogravimetric (DTG) technique using a thermobalance (TA Instruments, SDT 650, United States). The sample (10 mg) was heated between 27 and $800^{\circ}$ $\mathrm{C}$, with a heating rate of $10^{\circ} \mathrm{C} \cdot \mathrm{min}^{-1}$ at an inert atmosphere $\left(\mathrm{N}_{2}\right.$ gas $)$ with a flow of $40 \mathrm{~mL} \cdot \mathrm{min}^{-}$ 1 .

\subsection{Preparation of activated carbon}

Coconut leaves biochar (CLB) were produced by vacuum pyrolysis using a reactor composed of a tubular furnace (JUNG/LT6, $1 \mathrm{~kW}, 2010)$ heated by electric resistances. A temperature controller (NOVUS, 1043, Rio Grande do Sul, Brazil) was connected to keep the 
114 temperature at $500^{\circ} \mathrm{C}$ with a heating rate of $10^{\circ} \mathrm{C} \cdot \mathrm{min}^{-1}$. The system was also composed of 6 115 condensers responsible for condensing the process gases, collected in three decantation funnels

116 (CB1, CB2 and CB3). A thermostatic bath (Tecnal, TE-184, Brazil) was used to cool the liquid

117 products down to $4^{\circ} \mathrm{C}$. A vacuum pump (Fanem, 089/CAL, Brazil) was used to keep a negative

118 pressure of $20 \mathrm{kPa}$ within the system. Pyrolysis experiments were carried out in triplicate using

$119250 \mathrm{~g}$ of CL during a residence time of $2 \mathrm{~h}[17,20]$. Biochar and bio-oil yields were calculated 120 using Equation 1.

$$
\text { Yield }_{p}(\%)=\frac{m_{p}}{m_{l}} \times 100
$$

122 where $m_{p}$ is the produced mass of biochar and bio-oil $(\mathrm{g}) ; m_{l}$ is the initial mass of crude lignin

$123(\mathrm{~g})$; and Yield $_{p}$ is the product yield (\%). Gas yield was calculated by difference based on the 124 conservation of mass.

125 CLB samples were chemically activated using anhydrous potassium carbonate $\left(\mathrm{K}_{2} \mathrm{CO}_{3}\right)$ at a weight ratio of 1:3 (biochar: $\mathrm{K}_{2} \mathrm{CO}_{3}$ ). The mixture was homogenized using distilled water,

127 inserted in a porcelain pot and filled to the reactor under a pressure of $20 \mathrm{kPa}$ and heating rate 128 of $10^{\circ} \mathrm{C} \cdot \mathrm{min}^{-1}$ achieving $600^{\circ} \mathrm{C}$ for $1 \mathrm{~h}[18,19]$. The system was composed of a stainless steel 129 reactor (height of $20.0 \mathrm{~cm}$, diameter of $20.0 \mathrm{~cm}$ and volume of $6.8 \mathrm{~L}$ ) associated to a vacuum 130 pump (Fanem, 089/CAL, São Paulo, Brazil) and a temperature controller (Novus, N1200, 131 Campinas, Brazil). Steps involved in the activation of the biochar are: biochar maceration, 132 mixture homogenization, activation in the reactor, washing (neutralization) and drying. After 133 the activation, the coconut leaves activated carbon (CLAC) samples were cooled and washed 134 with distilled water to neutralize $(\mathrm{pH} 7)$ and to unblock the pores. After, biochar was decanted 135 and separated using a paper filter. Lastly, the sample was dried in the oven (Fanem, Orion 515, 136 São Paulo, Brazil) at $100^{\circ} \mathrm{C}$ overnight. 
138

139

140

141

142

143

144

145

146

147

148

149

150

151

152

153

154

155

156

157

158

159

160

161

162

\subsection{Characterizations}

The $\mathrm{N}_{2}$ adsorption/desorption analysis was conducted at $-195.91^{\circ} \mathrm{C}$ using a Micromeritics ASAP 2020 equipment 16. This analysis aimed to determine CLAC textural characteristics such as surface areas and pore diameter. The sample $(0.221 \mathrm{~g})$ was pre-treated at $100^{\circ} \mathrm{C}$ under vacuum for $12 \mathrm{~h}$. The specific area and the adsorption/desorption isotherms were estimated based on the Brunauer-Emmett-Teller (BET) method until a relative pressure of $\mathrm{P} / \mathrm{P}_{0}=0.97$ and by the average pore width in the adsorption. The X-ray diffraction (XRD) and patterns were recorded using a diffractometer (Shimadzu, DRX 6000, Japan), operating with a $\mathrm{Cu} \mathrm{K \alpha}(\lambda=0.1540598 \AA)$ radiation source in a $2 \theta$ range of $2-70^{\circ}$ with step of $0.02^{\circ}$. In this case, $0.1 \mathrm{~g}$ of the powder sample were analyzed using a voltage of $40 \mathrm{kV}$ and a current of $30 \mathrm{~mA}$. The analysis of $\mathrm{pH}$ at the point of zero charge ( $\mathrm{pH}$ PzC) was determined based on the methodology proposed by El-Sayed et al. [21]. In this case, $50 \mathrm{mg}$ of the sample was added in a $50 \mathrm{~mL}$ container of solution with the initial $\mathrm{pH}$ values ranging from 1 to 12 , these values were achieved adding $0.1 \mathrm{~mol} . \mathrm{L}^{-1}$ of $\mathrm{HCl}$ or $\mathrm{NaOH}$. The samples were mixed at $140 \mathrm{rpm}, 30^{\circ} \mathrm{C}$ for $24 \mathrm{~h}$, after that centrifuged to measure the $\mathrm{pH}$. Finally, inlet and outlet $\mathrm{pH}$ values were plotted to obtain the equilibrium $\mathrm{pH}$, which corresponds to the $p H_{P Z C}$ of the CLAC [16].

\subsection{Adsorption study}

\section{Kinetic study}

The kinetic study, were performed in a finite bath at $27 \pm 2^{\circ} \mathrm{C}$, with Erlenmeyers $(250$ $\mathrm{mL}$ ) were filled with $30 \mathrm{~mL}$ of CFN solution, in two different concentrations, 75 and $125 \mathrm{mg} . \mathrm{L}^{-}$ , and $50 \mathrm{mg}$ of activated biochar $\left(\mathrm{d}_{\mathrm{p}}<0.212 \mathrm{~mm}\right)$. The solutions were kept under constant agitation of $140 \mathrm{rpm}$ (Shaker SL 222 incubator) under time intervals between 2 and $120 \mathrm{~min}$ [17]. For each time, the samples were obtained and separated by centrifugation (Solab, SL700) for $5 \mathrm{~min}$ at 3,000 rpm. The concentration of CFN in the sample was obtained by a UV- 
163 vis spectrophotometer (Shimadzu, UV 1800 Spectrophotometer, Japan), at a wavelength of

$164272 \eta \mathrm{m}[17]$.The adsorption capacity $\left(q_{t}, \mathrm{mg} \cdot \mathrm{g}^{-1}\right)$ was calculated by Equation 2.

165

$$
q_{t}=\frac{\left(C_{0}-C_{f}\right)}{M} V
$$

166

167

where $\mathrm{C}_{0}$ is the initial $\mathrm{CFN}$ concentration, $\mathrm{V}$ is the solution volume and $\mathrm{M}$ is the mass of adsorbent.

To assess the kinetic comportment, the pseudo-first order [22], the pseudo-second order [23] and Weber-Morris [24] models, presented in Equations 3, 4 and 5, were used to fit the data.

$$
\begin{aligned}
& \mathrm{q}_{\mathrm{t}}=\mathrm{q}_{\mathrm{e}}\left[1-\exp \left(-\mathrm{k}_{1} * \mathrm{t}\right)\right] \\
& \mathrm{q}_{\mathrm{t}}=\frac{\mathrm{k}_{2} \mathrm{q}_{\mathrm{e}}^{2} \mathrm{t}}{1+\mathrm{k}_{2} \mathrm{q}_{\mathrm{e}}^{\mathrm{t}}} \\
& q_{t}=k_{d} t^{0,5}+I
\end{aligned}
$$

where $\mathrm{q}_{\mathrm{t}}\left(\mathrm{mg} \cdot \mathrm{g}^{-1}\right)$ is the adsorption capacity at $\mathrm{t}, \mathrm{t}(\mathrm{min})$ is the time, $\mathrm{q}_{\mathrm{e}}\left(\mathrm{mg} \cdot \mathrm{g}^{-1}\right)$ is the adsorption capacity at equilibrium, $\mathrm{k}_{1}\left(\mathrm{~min}^{-1}\right)$ is the constant of the pseudo-first order model, $\mathrm{k}_{2}(\mathrm{~g}$. $\left.{ }^{1} \mathrm{mg} \cdot \mathrm{min}^{-1}\right)$ is the constant for the pseudo-second order model; $k_{d}\left(\mathrm{mg} \cdot \mathrm{g}^{-1} \cdot \mathrm{min}^{-0.5}\right)$ is the intraparticle diffusion rate constant and $\mathrm{C}\left(\mathrm{mg} \cdot \mathrm{g}^{-1}\right)$ signifies the thickness of the boundary layer. [25-27].

\section{Equilibrium study}

The equilibrium experiments were carried out in a finite bath system, using $50 \mathrm{mg}$ of activated carbon $\left(d_{p}<0.212 \mathrm{~mm}\right)$ which was placed in a $250 \mathrm{ml}$ conical flask containing $30 \mathrm{ml}$ of CFN solution in concentrations $75,85,95,105,115,125,135$ and $145 \mathrm{mg} . \mathrm{L}^{-1}$. The solutions, in duplicate, were left in contact under agitation for 40 min (time defined in the adsorption kinetics experiments) at $140 \mathrm{rpm}, 30,40$ and $50^{\circ} \mathrm{C}$. After the contact time, the samples were centrifuged for $7 \mathrm{~min}$ at 3,000 rpm for separation between adsorbent and aqueous solution. The 
187 CFN final concentration was obtained using a UV-Vis spectrophotometer. The equilibrium 188 data were fitted using the nonlinear models, Langmuir [28], Freundlich [29], Sips [30] and 189 Redlich-Peterson [31],presented in the equations 5, 6, 7 and 8, respectively.

190

191

192

193

$$
q_{e}=\frac{q_{\max } \cdot K_{L} \cdot C_{e}}{1+K_{L} \cdot C_{e}}
$$

194

195

where $\mathrm{q}_{\max }\left(\mathrm{mg} \cdot \mathrm{g}^{-1}\right)$ is the adsorption capacity capacity, $\mathrm{k}_{\mathrm{L}}\left(\mathrm{L} \cdot \mathrm{mg}^{-1}\right)$ is the constant of 196 Langmuir model, $\mathrm{k}_{\mathrm{F}}\left(\mathrm{mg} \cdot \mathrm{g}^{-1}\right)\left(\mathrm{mg}^{\mathrm{L}} \mathrm{L}^{-1}\right)^{-1 / \mathrm{n}}$ is the constant of Freundlich model, $1 / \mathrm{n}(-)$ is the factor of heterogeneity, $\mathrm{q}_{\mathrm{S}}$ is the maximum adsorption capacity for the Sips model $\left(\mathrm{mg} \cdot \mathrm{g}^{-1}\right), \mathrm{K}_{\mathrm{S}}\left(\mathrm{L} \cdot \mathrm{mg}^{-1}\right)$ is the constant of Sips model and $\mathrm{ms}_{\mathrm{S}}(-)$ is the exponent of the Sips model, $\mathrm{k}_{\mathrm{R}}\left(\mathrm{L} \cdot \mathrm{mg}^{-1}\right)$, aR $\left(\mathrm{L} \cdot \mathrm{mg}^{-1}\right)^{\beta}$ and $\beta$ are constants for Redlich-Peterson.

\section{Statistical Evaluation}

The quality of models fit was evaluated by the coefficient of determination (R2), 203 average relative deviation (ARD), adjusted determination coefficient ( $\mathrm{R}^{2}$ adjus), and Akaike's 204 information criterion (AIC) given by equations 9, 10, 11 and 12, respectively.

$$
R^{2}=1-\frac{\sum_{i=1}^{n}\left(y_{i}^{e x p}-y_{i}^{c a l}\right)^{2}}{\sum_{i=1}^{n}\left(y_{i}^{e x p}-\bar{y}_{i}^{e x p}\right)^{2}}
$$

$$
A R D(\%)=\frac{100}{n} \sum_{i=1}^{n}\left|\frac{y_{i}^{e x p}-y_{i}^{c a l}}{y_{i}^{c a l}}\right|
$$

$$
R_{\text {adjus }}^{2}=1-\left(\frac{n-1}{1-\left(\mathrm{n}_{p}+1\right)}\right)\left(1+R^{2}\right)
$$




$$
A I C=n \ln -\frac{S Q E}{n}+2 \mathrm{n}_{p}+\left(\frac{2 \mathrm{n}_{p}\left(\mathrm{n}_{p}+1\right)}{n-\left(\mathrm{n}_{p}+1\right)}\right)\left(1+R^{2}\right)
$$

209 where $y_{i}^{\text {exp }}$ and $y_{i}^{c a l}$ are the experimental and calculated (model) values from dependent 210 variables $q_{t} ; n$ is the number of measured points; and $\bar{y}_{i}^{\exp }=\frac{\sum_{i=1}^{n} y_{i}^{\text {exp }}}{n}$ is used to calculate the 211 mean of the experimental values, $\mathrm{n}_{\mathrm{p}}$ is the number of model parameters [32].

\section{Thermodynamics}

Thermodynamics is an important used tool to understand the influences of temperature on

215 the adsorption mechanisms and their nature. The Gibbs free energy change $\left(\Delta \mathrm{G}^{\circ}\right)$, enthalpy change $216\left(\Delta \mathrm{H}^{\circ}\right)$, and entropy change $\left(\Delta \mathrm{S}^{\circ}\right)$ were determined using data from the isotherms and by Equations $217 \quad 13,14$ and $15[33,34]$.

$218 \Delta \mathrm{G}^{\mathrm{o}}=-\mathrm{RT} \ln \mathrm{K}_{\mathrm{e}}$

$\Delta \mathrm{G}^{\mathrm{o}}=\Delta \mathrm{H}^{\mathrm{o}}-\mathrm{T} \Delta \mathrm{S}^{\mathrm{o}}$

$220 \quad \ln \left(\mathrm{K}_{\mathrm{e}}\right)=\frac{-\Delta \mathrm{H}^{\mathrm{o}}}{\mathrm{RT}}+\frac{\Delta \mathrm{S}^{\mathrm{o}}}{\mathrm{R}}$

$221 \mathrm{R}$ is the universal constant of gases, $\mathrm{T}(\mathrm{K})$ is temperature, $\mathrm{K}_{\mathrm{e}}$ is the thermodynamic equilibrium

222 constant, which was determined by the constant of the isotherm model that best fit the experimental 223 data $[33,34]$.

224

\section{Ionic Strength and Influence of Aqueous Matrices}

Ionic strength tests were conducted at $\mathrm{NaCl}$ concentrations of 0,$5 ; 10,15$ and $30 \%(\mathrm{~m} / \mathrm{v})$.

227 The experiments were assessed at $30^{\circ} \mathrm{C}$ with $75 \mathrm{mg} \cdot \mathrm{L}^{-1}$ of caffeine solution in contact with $50 \mathrm{mg}$ of CLAC, at $140 \mathrm{rpm}$ for 40 min of contact. Subsequently, the liquid solution was separated

229 from solids by centrifugation for $7 \mathrm{~min}$ at 3,000 rpm. The final concentration of CFN was obtained using a UV-Vis spectrophotometer [35]. 
With the intention of assess the effect of different aqueous mediums on the caffeine

232

233

removal, adsorption experiments were achieved using lagoon (Mundaú Lagoon, Maceió/AL, Brazil), tap and mineral water. The initial caffeine concentration was $75 \mathrm{mg} . \mathrm{L}^{-1}, 50 \mathrm{mg}$ of CLAC, $30^{\circ} \mathrm{C}$ and 40 min contact time were used for the tests [36].

\section{Artificial neural networks}

In this work, neural networks were developed to compare their results with the traditional models in the literature used to predict kinetic and adsorption equilibrium data. The purpose of the neural model was also to assess its ability to generalize data. To do so, the adsorption kinetics data for the condition of $125 \mathrm{mg} . \mathrm{L}^{-1}$ and equilibrium data at the temperature of $40{ }^{\circ} \mathrm{C}$ were not included in the network database, being used in the network test and validation experiments. The other data referring to the other conditions studied were included in the database and consisted of network training experiments. The metrics used to assess the performance of the network developed and provide its comparison with theoretical models were the coefficient of determination and the average relative deviation.

The feed-forward neural model was used, with the Levenberg-Marquardt technique included into the backpropagation optimization process to calculate the weights and Bayesian regularization to prevent data overfitting. For the neurons in the hidden and output layers, hyperbolic tangent sigmoid and linear activation functions were employed, respectively. To increase the performance of the artificial neural network, the database was first normalized for the training stage, in order to remove any difficulties connected to the varied magnitudes of the data. The data normalization involved setting the rows of each data matrix to 0 and the deviations to 1. Optimization tests were done to establish the network's ideal structure once the database used for training trials was defined (number of neurons and number of intermediate layers). Thus, starting with the addition of one neuron, the size of the intermediate layer was 
changed, and changes in the R2 and ARD were continually monitored. This method was repeated until an optimal number of neurons and hidden layers were found, resulting in excellent output prediction outcomes and, at the same time, physically consistent values to a new pattern that was not addressed in the tests and has yet to be addressed.

\section{Results and Discussion}

\subsection{Raw material characterization}

The thermogravimetric analysis (TGA) and the differential thermal analysis (DTG) curves for coconut leaf are presented in Figure 1(a). This analysis is important to obtain information regarding the ideal temperatures for pyrolysis process. The degradation of biomass basically presents three zones. The first zone is up to $200{ }^{\circ} \mathrm{C}$, it is observed approximately $25 \%$ of weight loss. From this point it is observed the degradation of hemicellulose, cellulose and lignin begins. From 150 to $500{ }^{\circ} \mathrm{C}$ is the second zone, with a high mass loss rate, directly linked to the biomass carbonization process. In the third stage, there is a stabilization of the mass loss rate, which also indicates a decrease in the conversion process. Soon after, on the DTG curve, it was possible to observe the presence of two peaks: the first started between 200 and $235^{\circ} \mathrm{C}$, with a $12 \%$ of weight loss of hemicellulose degradation and the second, between 235 and 330 ${ }^{\circ} \mathrm{C}$ related to the cellulose degradation $[37,38]$. Lignin is a macromolecule that is difficult to decompose and presents showing a prominent degradation from $330^{\circ} \mathrm{C}$ until the stabilization at approximately $500{ }^{\circ} \mathrm{C}$. After that, the mass losses were minimized and defining this to be the best point for pyrolysis in order to obtain biochar. This behavior was similar to that described by Almeida et al. [39] who studied coconut fiber pyrolysis and Tsai et al. [40] who pyrolyzed the coconut fiber, sugarcane bagasse and rice husk. 
287

288

289

290

291

292

293

294

295

\subsection{Pyrolysis yield}

Pyrolysis experiments were performed in triplicate, with an initial mass of $250 \mathrm{~g}$ each.

With the results obtained it was possible to calculate the process yield using Equation 2 as shown in Table 1. Bridgwater [41], Goyal et al. [42] and Nayan et al. [43] in their studies defined a typical behavior for the pyrolysis process, $75 \%$ of bio-oil and $12 \%$ of biochar.

Table 1: Yield of pyrolysis of coconut leaf.

\begin{tabular}{cccccc}
\hline Product & $\begin{array}{c}\text { Yield } \\
\text { Run 1 }(\%)\end{array}$ & $\begin{array}{c}\text { Yield } \\
\text { Run 2 }(\%)\end{array}$ & $\begin{array}{c}\text { Yield } \\
\text { Run 3 }(\%)\end{array}$ & $\begin{array}{c}\text { Average } \\
(\%)\end{array}$ & $\begin{array}{c}\text { Standard } \\
\text { deviation }\end{array}$ \\
\hline Biochar & 32.44 & 35.68 & 33.84 & 33.99 & 2.29 \\
Bio-oil & 35.32 & 30.44 & 33.00 & 32.92 & 3.45 \\
Gas & 32.24 & 33.88 & 33.16 & 33.09 & 1.16 \\
\hline
\end{tabular}

\subsection{Characterizations}

Through $\mathrm{N}_{2}$ adsorption/desorption analysis was determined the CLAC surface area of $678.03 \mathrm{~m}^{2} / \mathrm{g}$, pore volume of $0.03 \mathrm{~cm}^{3} / \mathrm{g}$ and pore diameter of $45.48 \mathrm{~nm}$. Materials with pores between 20 and $50 \eta \mathrm{m}$, are classified as mesoporous, thus, the activated carbon of the coconut leaf is within this range [44]. The CFN molecule presents the dimensions $0.78 \mathrm{~nm} / 0.61 \mathrm{~nm} / 0.21$ $\mathrm{nm}$, this means that the pore diameter of the biochar, $45.48 \mathrm{~nm}$, is much larger than the dimensions of the CFN molecule, which allows the molecule to access the available active sites inside the pores for adsorption [45]. Regarding the surface area, the value of $678.03 \mathrm{~m}^{2} / \mathrm{g}^{-1}$ is acceptable for the adsorption process when related to the materials used for comparison [4651]. The $\mathrm{N}_{2}$ adsorption/desorption isotherms are shown in Figure 1(b), they are classified as type IV, characteristic of mesoporous material. The hysteresis also characterizes mesoporous materials and is suitable for the type IV isotherm model. The shape of hysteresis indicates a limitation. Despite easily adsorbing $\mathrm{N}_{2}$, it is not easily release it [32].

The CLAC XRD diffractogram pattern is presented in Figure 1(c) suggesting a typical amorphous characteristic. The diffraction peaks indicate an amorphous material. The broad 
303 peak at $2 \theta=23.32^{\circ}$ can be related to the typical silica characteristic, and the peak $2 \theta=42.96^{\circ}$

304 implies the formation of graphite with a turbostratic structure of amorphous carbon [52-55].

305 The point of zero charge for the activated carbon was 8.0. Thus, when the activated carbon is

306 in contact with a liquid solution in which the $\mathrm{pH}$ is below $\mathrm{pH}_{\mathrm{pzc}}$, it indicates that this surface is

307 positively charged. However, when the $\mathrm{pH}$ is above $\mathrm{pH}_{\mathrm{pzc}}$, the surface is negatively charged.

308 The chemical compounds are transformed into cations and anions depending on the pKa and

$309 \mathrm{pH}$ values of the solution [56]. Considering the CFN pKa $=8.3$, the adsorption at $\mathrm{pH}$ values

310 close to 8.0 occurs in the neutral form of the CFN molecule, confirmed by the experiments

311 presented in this work [13].

312 

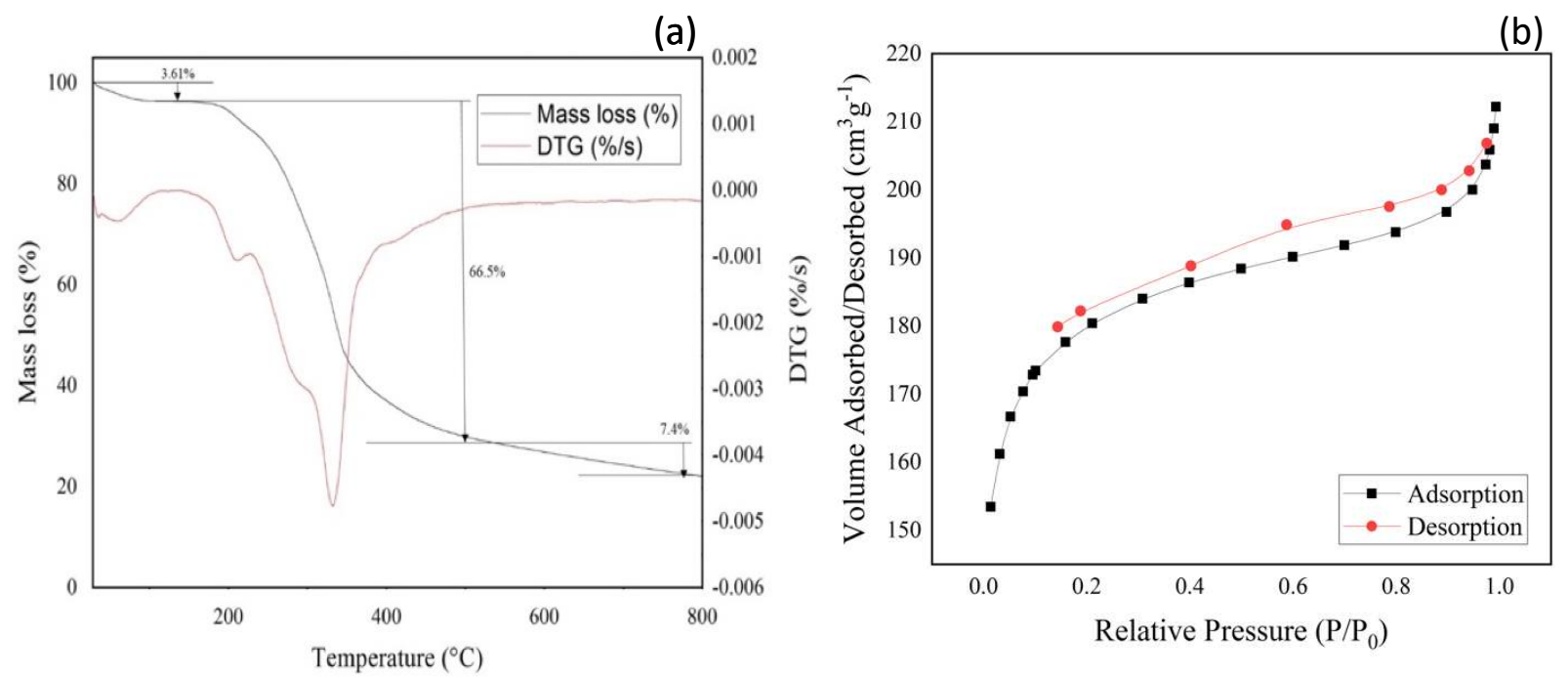

(c)

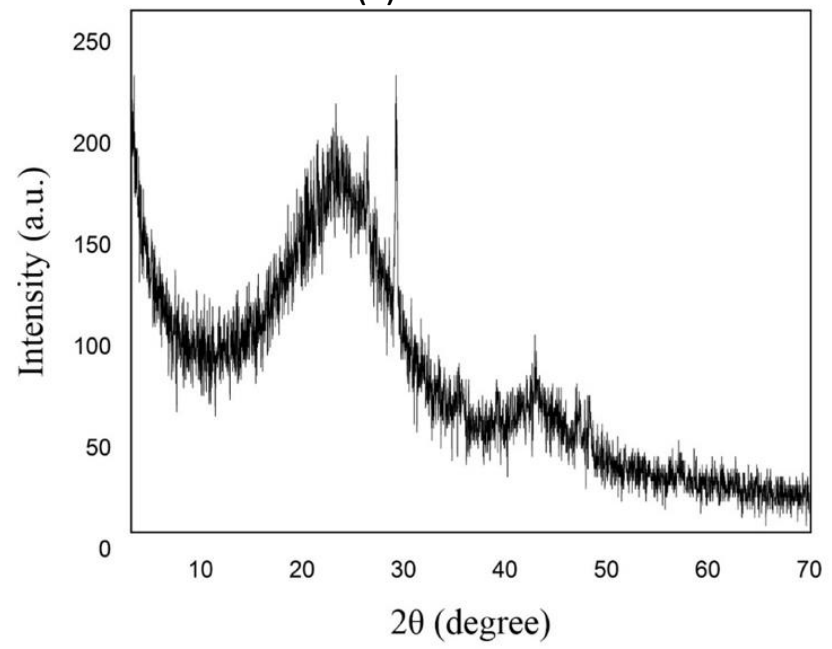

315 Figure 1: (a) Thermogravimetric analysis of the coconut leaf; (b) CLAC adsorption/desorption isotherm; and (c) CLAC XRD pattern 


\section{$318 \quad 3.4 \quad$ Adsorption study}

\section{$319 \quad$ Kinetic study}

Adsorption kinetic reveals the significant characteristic of adsorption, the transport rate

321 of the adsorbate to the adsorbent surface [57]. The kinetic curves are presented in the Figure

322 2(a), showing a typical behavior. At the beginning, a high adsorption rate was observed, reaching the equilibrium at $15 \mathrm{~min}\left(44.0 \mathrm{mg} \cdot \mathrm{g}^{-1}\right)$ and $30 \mathrm{~min}\left(64.0 \mathrm{mg} \cdot \mathrm{g}^{-1}\right)$ for 75 and $125 \mathrm{mg} \cdot \mathrm{g}^{-}$

324 , respectively. Such a behavior, the fast initial adsorption may be associated with the large availability of surface area and active sites. The concentration difference between the solution bulk and the adsorbent surface can act as a driving force to overcome mass transfer barrier.

327 After this initial step, the surface area and sites are gradually blocked and, instead, the adsorption rate decreases. The quantity of desorbing adsorbate on the adsorbent surface and the amount of adsorbent adsorbate on the surface are in dynamic equilibrium at this moment. Another issue to be addressed is that at higher concentrations the adsorption capacity is higher. This is because at high concentrations there are more molecules occupying the available active sites [57-60].

In order to understand the dynamics of interactions between caffeine and activated carbon, the kinetic models of pseudo-first order (PFO), pseudo-second order (PSO) and intraparticle diffusion were adjusted to the experimental data and the parameters are presented in Table 2. The higher coefficients of determination $\left(\mathrm{R}^{2}>0.89\right)$ and lower average relative

337 deviation showed a better fit of the experimental data to the pseudo-second order model.

338 Despite the fact that neither PFO and PSO models describe the adsorption mechanism, the difference between the mean solid phase concentration and the equilibrium concentration is assumed to represent the driving factor for adsorption by both models. In this case, the 
341 adsorption rate for the PFO model would be proportional to the driving force, while for the

342 PSO model, it would be proportional to the square of the driving force [61-63].

343 Figure 2(b) show the adjustment of the experimental data to the intraparticle diffusion

344 model. When plotting $\mathrm{q}_{\mathrm{t}}$ as a function of $\mathrm{t}^{0.5}$, the intraparticle diffusion step will govern

345 adsorption if the resulting curve is linear and passes through the origin. If two phases can be

346 distinguished, the first curve represents diffusion in the particle's outer layer, while the second

347 curve represents diffusion in the particle's inner layer. As a result, the two stages of external

348 diffusion and intraparticle diffusion regulate caffeine adsorption by coconut leaves activated

349 carbon (CLAC) $[27,35,64]$.

\section{Equilibrium study}

In order to comprehend the mechanism of interaction amid the caffeine molecules and the coconut leaves activated carbon the adsorption isotherms were obtained, shown in Figure 2 (c-e). Giles et al. [65] describes a classification of solid-liquid isotherm and suggests that its shape can be used to define the adsorption mechanism, physical nature of the solute, substrate surface and specific product surface area. Thus, the obtained isotherms can be considered type L2, that presents an initial curvature facing downwards, indicating a reduction in the availability of active sites with the increase of adsorbate concentration. As more places in the adsorbent surface are occupied, it becomes more difficult for the CFN molecules to find an empty spot. The plateaus suggest that all available locations on the original adsorbent surface were filled [34,59].

To better understand the adsorption mechanism, non-linear isothermal models were used to fit the experimental data. Therefore, four models were tested: Langmuir, Freundlich,

364 Redlich-Peterson and Sips. The results are presented in Table 2. Considering $\mathrm{R}^{2}$ values, all models have values above 0.98 , which makes this criterion not decisive. The second statistical 
366 criterion analyzed was the $\mathrm{R}^{2}$ adj, where the best values were for the Redlich-Peterson and Sips

367 models. The smallest ARE values was obtained for the Redlich-Peterson model. However,

368 according to the AIC criterion, the lowest values was for the Freundlich model. Yet, the

369 Redlich-Peterson model has components of the Langmuir and Freundlich equations. For the

370 constant $\beta$ values close to 1 the Redlich-Peterson model presents Freundlich characteristics,

371 and for $\beta$ values close to 0 it presents Langmuir characteristics, so in the Redlich-Peterson

372 model can represent the equilibrium data caffeine adsorption onto coconut leaves activated

373 carbon

374 Finally, Table 3 compares the adsorption performances of alternative adsorbents in 375 order to cover the adsorbent's future applicability to various contaminants. It can be noted that

376 the adsorption capacity findings obtained are on the same order of magnitude as those obtained 377 in the current work, checking the positive result achieved. 
379

380

381

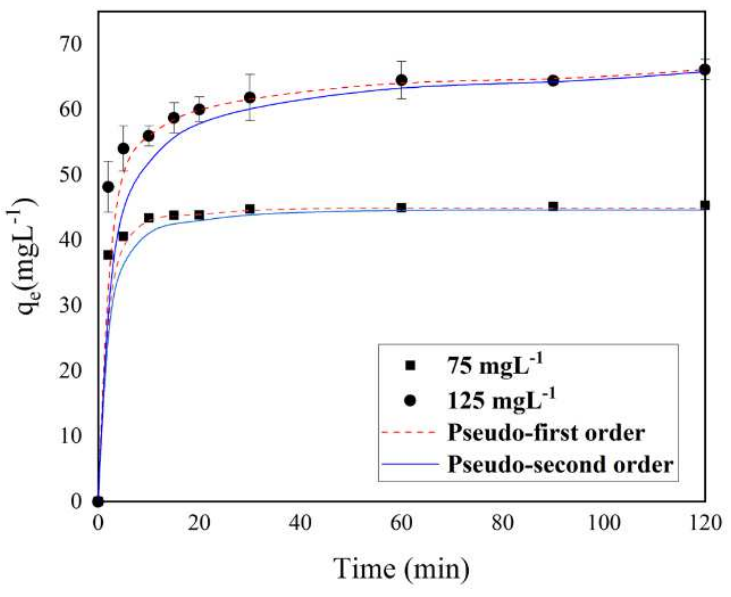

(a)

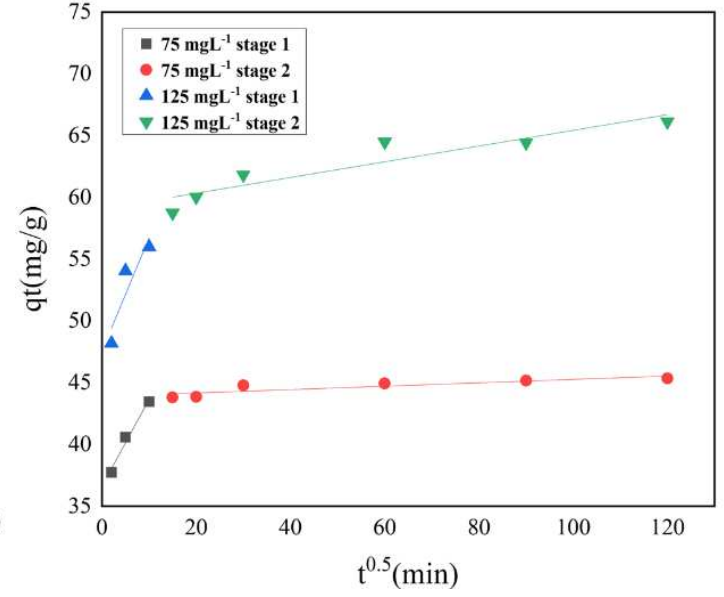

(b)

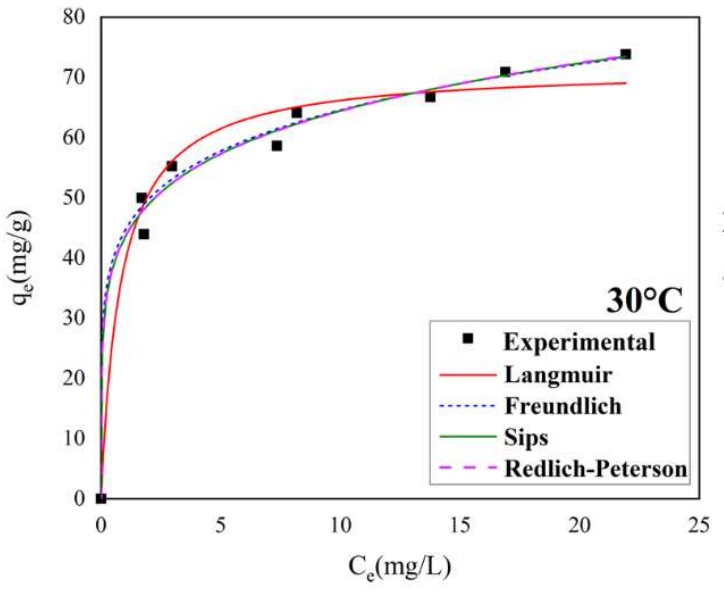

(c)

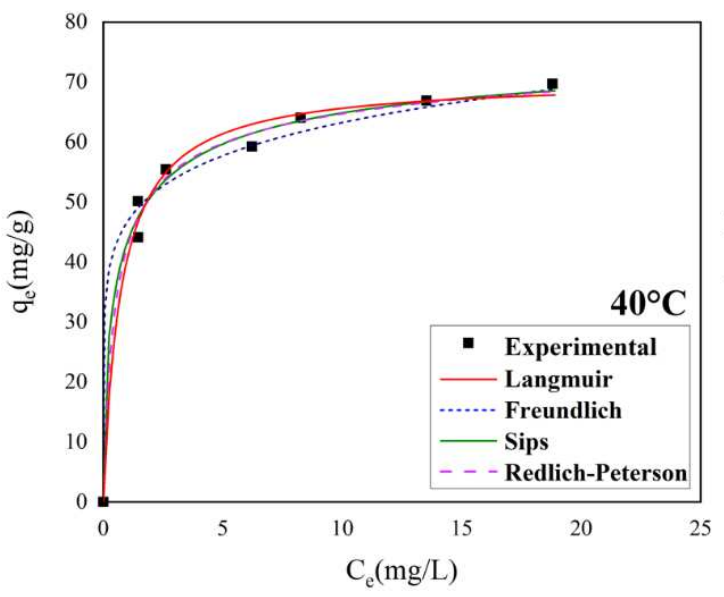

(d)

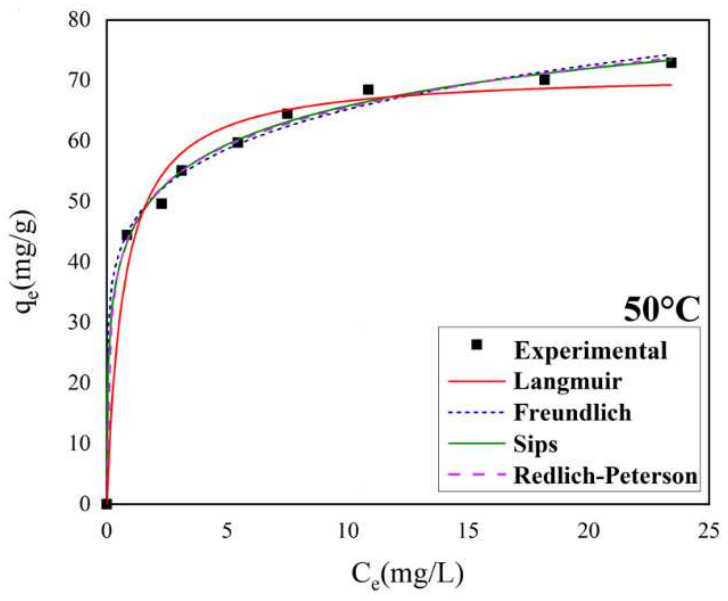

(e)

Figure 2: (a) Kinetic curves; (b) Weber-Morris intraparticle diffusion model and adsorption isotherms at (c) $30{ }^{\circ} \mathrm{C}$, (d) $40{ }^{\circ} \mathrm{C}$ and (e) $50{ }^{\circ} \mathrm{C}$. 
Table 2: Kinetic, equilibrium and thermodynamic parameters for CFN adsorption using

CLAC

\begin{tabular}{|c|c|c|c|c|}
\hline \multicolumn{5}{|c|}{ Kinetic } \\
\hline Model & \multicolumn{2}{|c|}{ Parameters } & $75{\mathrm{mg} . \mathrm{L}^{-1}}^{1}$ & $125{\mathrm{mg} . \mathrm{L}^{-1}}^{-1}$ \\
\hline \multirow{4}{*}{ Pseudo-First Order } & & 0.744 & 0.644 \\
\hline & \multirow{3}{*}{\multicolumn{2}{|c|}{$\begin{array}{c}\mathrm{q}_{\mathrm{e}}\left(\mathrm{mg} \cdot \mathrm{g}^{-1}\right) \\
\operatorname{ARD}(\%) \\
\mathrm{k}_{1}\left(\min ^{-1}\right)\end{array}$}} & 43.68 & 59.53 \\
\hline & & & 0.203 & 3.73 \\
\hline & & & 0.9657 & 0.7843 \\
\hline \multirow{4}{*}{ Pseudo-Second Order } & \multirow{4}{*}{\multicolumn{2}{|c|}{$\begin{array}{c}\mathrm{R}^{2} \\
\mathrm{q}_{\mathrm{e}}\left(\mathrm{mg}^{-\mathrm{g}^{-1}}\right) \\
\operatorname{ARD}(\%) \\
\mathrm{k}_{2}\left(\mathrm{~min}^{-1}\right) \\
\end{array}$}} & 0.963 & 0.893 \\
\hline & & & 45.01 & 63.69 \\
\hline & & & 0.87 & 2.45 \\
\hline & & & 0.0537 & 0.0240 \\
\hline \multicolumn{5}{|c|}{ Equilibrium } \\
\hline Model & Parameter & $\mathbf{3 0}^{\circ} \mathrm{C}$ & $40^{\circ} \mathrm{C}$ & $5^{\circ}{ }^{\circ} \mathbf{C}$ \\
\hline \multirow{7}{*}{ Langmuir } & $\mathrm{q}_{\exp (\max )}(\mathrm{mg} / \mathrm{g})$ & 73.83 & 69.79 & 72.94 \\
\hline & $\mathrm{q}_{\text {calc(max }}(\mathrm{mg} / \mathrm{g})$ & 73.13 & 70.51 & 71.39 \\
\hline & $\mathrm{K}_{\mathrm{L}}(\mathrm{L} / \mathrm{mg})$ & 1.343 & 0.987 & 1.393 \\
\hline & $\mathrm{R}^{2}$ & 0.980 & 0.989 & 0.976 \\
\hline & $\mathrm{R}_{\text {ajustado }}^{2}$ & 0.40 & 0.40 & 0.40 \\
\hline & ARD & 3.96 & 2.99 & 4.83 \\
\hline & AIC & 22.97 & 18.72 & 24.85 \\
\hline \multirow{6}{*}{ Freundlich } & $\mathrm{n}$ & 5.89 & 7.56 & 6.54 \\
\hline & $\mathrm{K}_{\mathrm{F}}\left[(\mathrm{mg} / \mathrm{L})(\mathrm{L} / \mathrm{g})^{1 / \mathrm{n}}\right]$ & 43.55 & 46.66 & 45.87 \\
\hline & $\mathrm{R}^{2}$ & 0.989 & 0.987 & 0.994 \\
\hline & $\mathrm{R}_{\text {ajustado }}^{2}$ & 0.40 & 0.40 & 0.40 \\
\hline & ARD & 3.61 & 3.09 & 1.95 \\
\hline & AIC & 19.66 & 19.10 & 13.02 \\
\hline \multirow{7}{*}{ Redlich-Peterson } & $\mathrm{K}_{\mathrm{R}}(\mathrm{L} / \mathrm{mg})$ & 292.00 & 149.76 & 599.29 \\
\hline & $\mathrm{a}(\mathrm{L} / \mathrm{mg})^{\beta}$ & 12.75 & 2.52 & 12.39 \\
\hline & B & 0.847 & 0.943 & 0.867 \\
\hline & $\mathrm{R}^{2}$ & 0.989 & 0.992 & 0.998 \\
\hline & $\mathrm{R}_{\text {ajustado }}^{2}$ & 0.75 & 0.75 & 0.75 \\
\hline & ARD & 3.61 & 2.83 & 1.92 \\
\hline & AIC & 25.16 & 21.96 & 18.05 \\
\hline \multirow{7}{*}{ Sips } & $\mathrm{q}_{\max }(\mathrm{mg} / \mathrm{g})$ & 158.99 & 78.22 & 115.39 \\
\hline & $\mathrm{K}_{\mathrm{s}}(\mathrm{L} / \mathrm{mg})$ & 0.367 & 1.235 & 0.633 \\
\hline & $\mathrm{m}_{\mathrm{S}}$ & 0.271 & 0.594 & 0.322 \\
\hline & $\mathrm{R}^{2}$ & 0.989 & 0.992 & 0.996 \\
\hline & $\mathrm{R}^{2}{ }_{\text {ajustado }}$ & 0.75 & 0.75 & 0.75 \\
\hline & ARD & 3.77 & 2.82 & 1.90 \\
\hline & AIC & 25.26 & 22.08 & 16.89 \\
\hline \multirow{3}{*}{ Thermodynamics } & $\Delta \mathrm{G}^{\mathrm{o}}\left(\mathrm{kJ} \cdot \mathrm{mol}^{-1}\right)$ & -49.10 & -48.99 & -54.28 \\
\hline & $\Delta \mathrm{H}^{\mathrm{o}}\left(\mathrm{kJ} \cdot \mathrm{mol}^{-1}\right)$ & & -28.35 & \\
\hline & $\Delta \mathrm{S}^{\mathrm{o}}\left(\mathrm{kJ} \cdot \mathrm{mol}^{-1}\right)$ & & 0.253 & \\
\hline
\end{tabular}


Table 3: Comparison of some adsorbents for caffeine adsorption

\begin{tabular}{lccc}
\hline \multicolumn{1}{c}{ Adsorbent } & $\begin{array}{c}\mathbf{q m a x} \\
(\mathbf{m g} / \mathbf{g})\end{array}$ & Conditions & Reference \\
\hline $\begin{array}{lccc}\text { Combined powder and granulated activated } \\
\text { carbon }\end{array}$ & 12.63 & $24 \mathrm{~h}, 20{ }^{\circ} \mathrm{C}$ & {$[66]$} \\
Synthetic xerogel coals & 182.5 & $48 \mathrm{~h}, 30{ }^{\circ} \mathrm{C}$ & {$[67]$} \\
Oxidized carbon derived from Luffa cylindrica & 59.88 & $24 \mathrm{~h}, 25{ }^{\circ} \mathrm{C}$ & {$[68]$} \\
Pine needle biochar & 6.54 & $150 \mathrm{~min}, 40$ & {$[69]$} \\
& 155.5 & $4 \mathrm{~h}, 25-55^{\circ} \mathrm{C}$ & {$[70]$} \\
Activated pineapple leaf biochar & 19.55 & $16 \mathrm{~h}, 25{ }^{\circ} \mathrm{C}$ & {$[71]$} \\
Fique bagasse biochar & 4.18 & $2 \mathrm{~h}, 25{ }^{\circ} \mathrm{C}$ & {$[72]$} \\
Commercial multi-walled carbon nanotubes & 88.00 & $2 \mathrm{~h}, 25{ }^{\circ} \mathrm{C}$ & {$[72]$} \\
Commercial granulated activated carbon & 26.219 & $30 \mathrm{~min}, 40{ }^{\circ} \mathrm{C}$ & {$[14]$} \\
MgAl-LDH / Bovine bone biochar & 270.0 & $3 \mathrm{days}, 30^{\circ} \mathrm{C}$ & {$[73]$} \\
Fixed bed activated carbon & 48.7 & $12 \mathrm{~h}, 25{ }^{\circ} \mathrm{C}$ & {$[74]$} \\
Sepiolite clay & 73.83 & $40 \mathrm{~min}, 30^{\circ} \mathrm{C}$ & This work \\
Coconut leaf activated carbon & & & \\
\hline
\end{tabular}

391 Thermodynamic study

Using the equilibrium data obtained at 30,40 and $50^{\circ} \mathrm{C}$ it was possible to determine

393 the thermodynamic parameters, Gibbs free energy $\left(\Delta \mathrm{G}^{\circ}\right)$, enthalpy $\left(\Delta \mathrm{H}^{\circ}\right)$ and entropy $\left(\Delta \mathrm{S}^{\circ}\right)$

394 using the procedure presented by Piccin et al [34]. The free energy values of Gibbs $\left(\Delta \mathrm{G}^{\circ}\right)$,

395 enthalpy $\left(\Delta \mathrm{H}^{\circ}\right)$ and entropy $\left(\Delta \mathrm{S}^{\circ}\right)$ are showed in Table 2. The negative values of $\Delta \mathrm{G}^{\circ}$

396 determine that the adsorption is spontaneous and favorable. In addition, the positive $\Delta \mathrm{S}^{\circ}$ value

397 indicates that there was a change in the structure of the adsorbent and an increase in randomness

398 during $\mathrm{CFN}$ fixation in active sites. $\Delta \mathrm{H}^{\circ}$ negative value indicate the adsorption is exothermic.

399 The negative and low $\Delta \mathrm{H}^{\circ}$ values indicate the weak adsorption forces and physical and 400 exothermic nature[12,75-77].

401 
404 is depicted in Figure 3(a). Despite changing the ionic strength of the solution, the adsorption capacity of the CLAC remained nearly constant, according to the experimental results. As a result, electrostatic interactions have no effect on the adsorption of caffeine onto CLAC. important complementary step in this study. The collected data of this step is presented in Figure 409 3(b). The removal was 44.7, 40.8 and $65.9 \%$ for lagoon, tap and mineral water, respectively. The delineated results endorse the validity and applicability of CLAC for caffeine removal in different 411 water mediums.

412

413

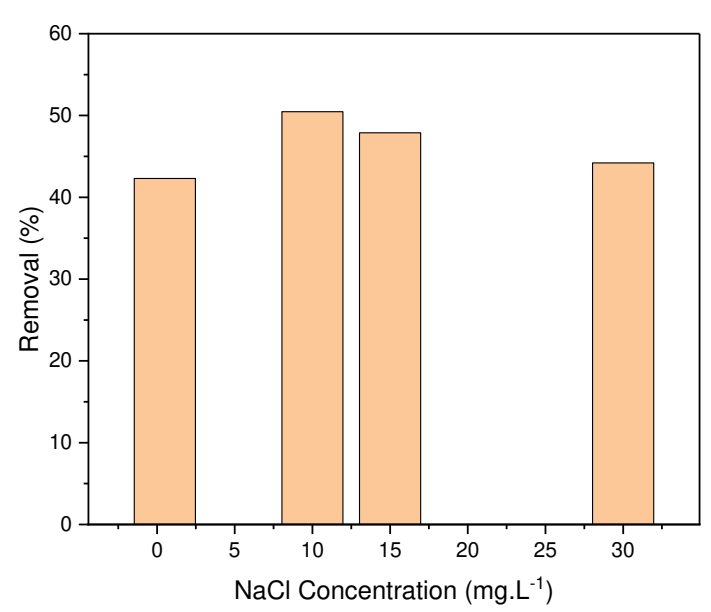

(a)

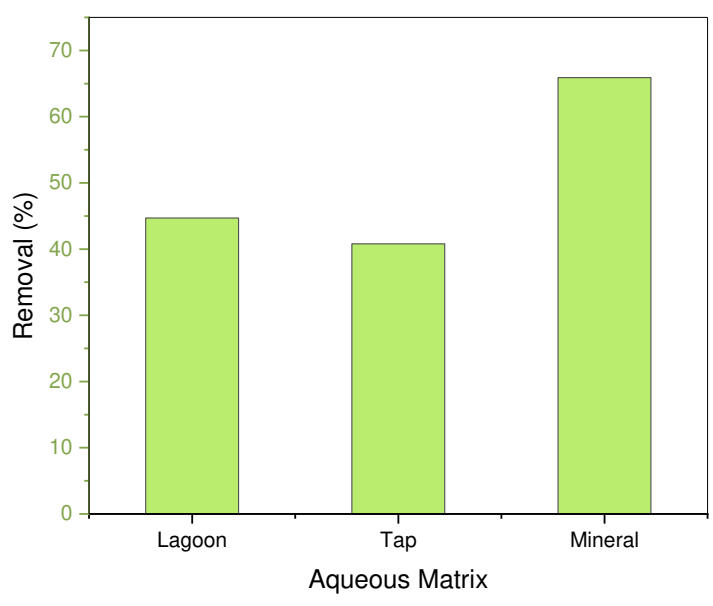

(b)

Figure 3: (a) Effect of ionic strength; (b) effect of aqueous matrices

\subsection{Artificial neural networks}

The results of the neural network predictions for the adsorption kinetic data and equilibrium isotherms are presented in Figures 5 and 6, respectively. As it can be seen in the results presented, the developed neural network was adequate to predict the kinetics adsorption data, but it had difficulty in predicting the adsorption equilibrium data for values of $\mathrm{C}_{\mathrm{e}}$ lower than $5 \mathrm{mg} . \mathrm{L}^{-1}$ for the data not used in the training step (Figure 6.b), but there is room for improvement of the network. It must be taken into account, however, that $\mathrm{C}_{\mathrm{e}}$ values are 
423 different for each temperature condition tested, that is, the amount adsorbed at equilibrium is 424 dependent on the concentration values for each temperature condition. As a neural model is a 425 model that interpolates values, the global adjustment is compromised, given the network's 426 difficulty in structuring its learning in the face of the non-uniformity of the independent 427 variable's data. 


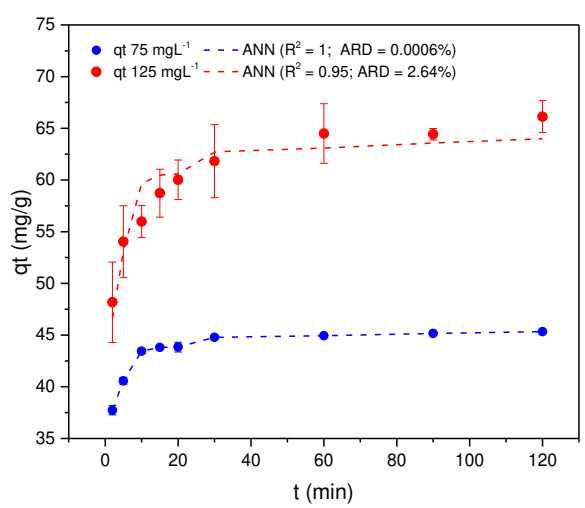

Figure 5: Observed and predicted equilibrium data by the neural model developed in this work. The condition $\mathrm{q}_{\mathrm{t}}=125 \mathrm{mg} . \mathrm{L}^{-1}$ (red color) corresponds to the ANN testing experiments.
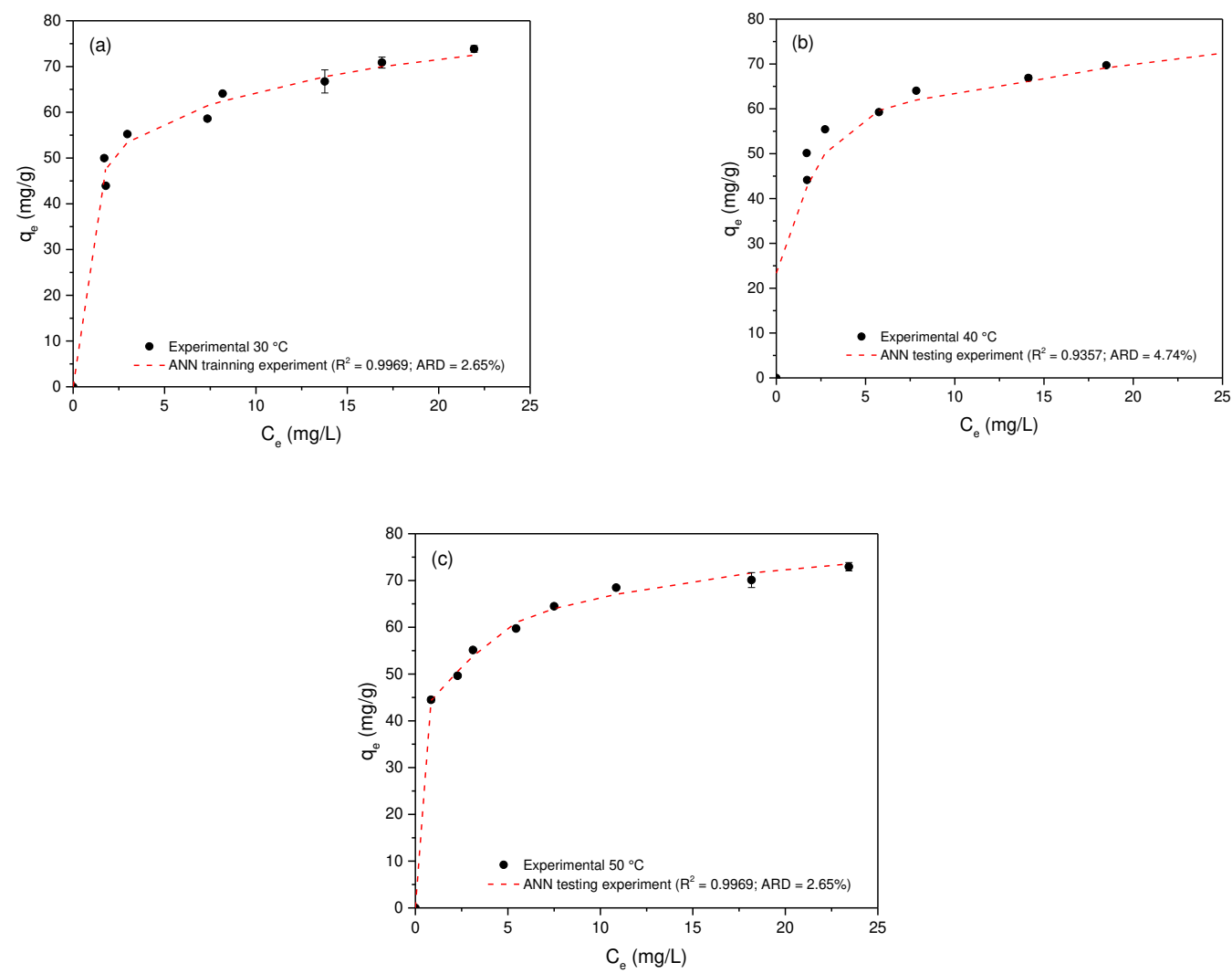

$434 \quad$ Figure 6: Observed and predicted equilibrium data by the neural model developed in this condition of $40^{\circ} \mathrm{C}$; (c) training experiments for the condition of $50^{\circ} \mathrm{C}$. 
438 kinetics, in which, for the same time interval, the network performance was satisfactory, even

439

440

441

442

443

444

445

446

447

448

449

450

451

452

453

454

455

456

457

458

459

460

461

considering only the adsorption kinetic data for the dataset of the $125 \mathrm{mg} . \mathrm{L}^{-1}$ condition. These

results do not detract from the neural network, which, in addition to presenting a good performance for adsorption kinetics, proved to be an excellent tool to predict equilibrium data for the other analyzed temperature conditions used in its database (figures 6 a and c). In fact, with a more efficient database, the neural network could be more accurate. Even so, for data not used in the training step, the $A R D$ value was below $5 \%$, encouraging its use for future studies on the optimization of effluent adsorption processes using the solid waste of an organic nature, both regarding kinetics and isotherms of adsorption.

It is worth mentioning that the developed neural network presented a very simple structure and low computational cost, with no tendencies towards the overfitting problem. The resulting mathematical model is simple and can be used with good accuracy to predict caffeine adsorption data using coconut leaf residues within the range of operating conditions studied. The coefficient of determination was greater than 0.99 for the training experiments and equal to the unity for the kinetic experiments. Little data was used in the training of the network, which reinforces its good performance. The $A R D$ value was below $5 \%$ in all the cases analyzed, showing a very little deviation from the experimental values.

In comparison with the classical models presented in the literature, such as the Langmuir, Freundlich, Redlich-Peterson, and Sips models, the accuracy of the neural network was comparable to these models in predicting the data used in the training experiments. It should be noted that these models do not have the ability for data generalization. Similar results were also found for the adsorption kinetics experiments.

\section{Conclusion}


From the results obtained in this study, the coconut leaf activated carbon achieved good

463

464

results of caffeine adsorption reaching a maximum theoretical adsorption capacity of 73.83 $\mathrm{mg} \cdot \mathrm{g}^{-1}$ at $30^{\circ} \mathrm{C}$ in $40 \mathrm{~min}$ of adsorption. The pseudo-second order model adequately described the kinetic data and the Redlich-Peterson model well fitted the equilibrium isotherms. The adsorption was exothermic, spontaneous and favorable. It was determined a change in the structure of the adsorbent and an increase in the randomness during CFN fixation in active sites. The ionic strength of the solution has no effect on the adsorption of caffeine onto CLAC. The studied adsorbent demonstrated be suitable for caffeine removal in different water mediums. The artificial neural networks developed in this work were capable of predicting both kinetics and equilibrium adsorption data under different operating conditions. Even for data not used in the network database in the training experiments, the highest mean absolute percentage error obtained was less than $5 \%$, showing that the neural model can be considered an interesting tool for future studies on optimization of adsorption processes and data generalization. The neural model also proved to be comparable to the traditional theoretical models presented in the literature for predicting isotherm and adsorption kinetics data. Finally, the coconut leaf activated carbon, unexplored for this use, appears to be an exceptional alternative adsorbent, as it is an abundant biomass available at low cost.

\section{Acknowledgement}

The authors thank to National Council for Scientific and Technological Development (CNPq/Brazil), Coordination for the Improvement of Higher Education Personnel (CAPES/Brazil) and Foundation for Research Support of the State of Alagoas (FAPEAL/ Brazil).

\section{References}

[1] S.R. Kappil, R. Aneja, P. Rani, Decomposing the performance metrics of coconut 
cultivation in the South Indian States, Humanit. Soc. Sci. Commun. 8 (2021) 114.

[2] F. and A.O. FAO, FAOSTAT, 2020.

[3] S.S. Sekhon, P. Kaur, J.S. Park, From coconut shell biomass to oxygen reduction reaction catalyst: Tuning porosity and nitrogen doping, Renew. Sustain. Energy Rev. 147 (2021) 111173. https://doi.org/10.1016/J.RSER.2021.111173.

[4] M.D. Bispo, J.K. Schneider, D. Da Silva Oliveira, D. Tomasini, G.P. Da Silva MacIel, T. Schena, B. Onorevoli, T.R. Bjerk, R.A. Jacques, L.C. Krause, E.B. Caramão, Production of activated biochar from coconut fiber for the removal of organic compounds from phenolic, J. Environ. Chem. Eng. 6 (2018) 2743-2750. https://doi.org/10.1016/j.jece.2018.04.029.

[5] Y. Al-Degs, M.A.M. Khraished, S.J. Allen, M.N.A. Ahmad, Sorption behavior of cationic and anionic dyes from aqueous solution on different types of activated carbons, Sep. Sci. Technol. 36 (2001) 91-102.

[6] K. Rouquerol, F.; Rouquerol, J.; Sing, Adsorption by powders \& porous solids: principles, methodology and applications., Academic Press, San Diego - USA, 1999.

[7] L. Meili, P.V.S. Lins, M.T. Costa, R.L. Almeida, A.K.S. Abud, J.I. Soletti, G.L. Dotto, E.H. Tanabe, L. Sellaoui, S.H.V. Carvalho, A. Erto, Adsorption of methylene blue on agroindustrial wastes: Experimental investigation and phenomenological modelling, Prog. Biophys. Mol. Biol. (2018). https://doi.org/10.1016/j.pbiomolbio.2018.07.011.

[8] V. Geissen, H. Mol, E. Klumpp, G. Umlauf, M. Nadal, M. van der Ploeg, S.E. a. T.M. van de Zee, C.J. Ritsema, Emerging pollutants in the environment: A challenge for water resource management, Int. Soil Water Conserv. Res. 3 (2015) 57-65. https://doi.org/10.1016/j.iswcr.2015.03.002.

[9] Y. Patino, E. Diaz, S. Ordonez, Performance of different carbonaceous materials for emerging pollutants adsorption, Chemosphere. 119 (2015) S124-S130. 
512

513

514

https://doi.org/10.1016/j.chemosphere.2014.05.025.

[10] Y. Patiño, E. Díaz, S. Ordóñez, E. Gallegos-Suarez, A. Guerrero-Ruiz, I. RodríguezRamos, Adsorption of emerging pollutants on functionalized multiwall carbon nanotubes, Chemosphere. 136 (2015) 174-180. https://doi.org/10.1016/j.chemosphere.2015.04.089.

[11] M.K. Arfanis, P. Adamou, N.G. Moustakas, T.M. Triantis, A.G. Kontos, P. Falaras, Photocatalytic degradation of salicylic acid and caffeine emerging contaminants using titania nanotubes, Chem. Eng. J. (2016). https://doi.org/10.1016/j.cej.2016.06.098.

[12] P.V.S. Lins, D.C. Henrique, A.H. Ide, J.L. da S. Duarte, G.L. Dotto, A. Yazidi, L. Sellaoui, A. Erto, C.L. de P. e S. Zanta, L. Meili, Adsorption of a non-steroidal antiinflammatory drug onto $\mathrm{MgAl} / \mathrm{LDH}$ - activated carbon composite - Experimental investigation and statistical physics modeling, Colloids Surfaces A Physicochem. Eng. Asp. (2019). https://doi.org/10.1016/j.colsurfa.2019.124217.

[13] R.C. Ferreira, O.M. Couto Junior, K.Q. Carvalho, P.A. Arroyo, M.A.S.D. Barros, Effect of Solution pH on the Removal of Paracetamol by Activated Carbon of Dende Coconut Mesocarp, Chem. Biochem. Eng. Q. J. 29 (2015) 47-53. https://doi.org/10.15255/cabeq.2014.2115.

[14] P.V. dos Santos Lins, D.C. Henrique, A.H. Ide, C.L. de Paiva e Silva Zanta, L. Meili, Evaluation of caffeine adsorption by MgAl-LDH/biochar composite, Environ. Sci. Pollut. Res. (2019). https://doi.org/10.1007/s11356-019-06288-3.

[15] C. Barbas, A. Garcıa, L. Saavedra, M.C. Castró, C. Castró”, Optimization and validation of a method for the determination of caffeine, 8-chlorotheophylline and diphenhydramine by isocratic high-performance liquid chromatography Stress test for stability evaluation, 2000. www.elsevier.com/locate/chroma.

[16] K.K. Beltrame, A.L. Cazetta, P.S.C. de Souza, L. Spessato, T.L. Silva, V.C. Almeida, 
Adsorption of caffeine on mesoporous activated carbon fibers prepared from pineapple plant leaves, Ecotoxicol. Environ. Saf. 147 (2018) 64-71. https://doi.org/10.1016/j.ecoenv.2017.08.034.

[17] L.K.F. Araújo, A.A. Albuquerque, W.C.O. Ramos, A.T. Santos, S.H. V. Carvalho, J.I. Soletti, M.D. Bispo, Elaeis guineensis-activated carbon for methylene blue removal: adsorption capacity and optimization using CCD-RSM, Environ. Dev. Sustain. (2021). https://doi.org/https://doi.org/10.1007/s10668-020-01137-7.

[18] K.J.L. dos Santos, G.E. de Souza dos Santos, Í.M.G.L. de Sá, S.H.V. de Carvalho, J.I. Soletti, L. Meili, J.L. da Silva Duarte, M.D. Bispo, G.L. Dotto, Syagrus oleraceaactivated carbon prepared by vacuum pyrolysis for methylene blue adsorption, Environ. Sci. Pollut. Res. (2019). https://doi.org/10.1007/s11356-019-05083-4.

[19] K.J.L. dos Santos, G. de Souza dos Santos, Í.M.G.L. de Sá, A.H. Ide, J.L. da Silva Duarte, S.H. Vieira de Carvalho, J.I. Soletti, L. Meili, Wodyetia bifurcata Biochar for methylene blue removal from aqueous matrix, Bioresour. Technol. 293 (2019) 122093. https://doi.org/10.1016/j.biortech.2019.122093.

[20] L.V.O. Sandes, • W T Vieira, • A A Albuquerque, • P X O Bezerra, • L M O Ribeiro, • S H V Carvalho, • J I Soletti, • M D Bispo, Pyrolysis of Lignocellulosic Waste from Second-Generation Ethanol Industry, Sugar Tech. 23 (n.d.). https://doi.org/10.1007/s12355-020-00941-9.

[21] G.O. El-Sayed, M.M. Yehia, A.A. Asaad, Assessment of activated carbon prepared from corncob by chemical activation with phosphoric acid, Water Resour. Ind. 7-8 (2014) 66-75.

[22] S. Lagergren, About the theory of so-called adsorption of soluble substances, K. Sven. Vetenskapsakademiens. 24 (1898) 1-39.

[23] Y.S. Ho, G. McKay, Pseudo-second order model for sorption processes, Process 
562

563

564

565

566

567

568

569

570

571

572

573

574

575

576

577

578

579

580

581

582

583

584

585

586

Biochem. 34 (1999) 451-465. https://doi.org/10.1016/S0032-9592(98)00112-5.

[24] W.J. Weber, J.C. Morris, Kinetics of Adsorption on Carbon from Solution, J. Sanit. Eng. Div. 89 (1963) 31-60.

[25] L.C. Santos, A.F. da Silva, P.V. dos S. Lins, J.L. da S. Duarte, A.H. Ide, L. Meili, MgFe layered double hydroxide with chloride intercalated : synthesis , characterization and application for efficient nitrate removal, Environ. Sci. Pollut. Res. (2019). https://doi.org/https://doi.org/10.1007/s11356-019-07364-4.

[26] A. Özer, G. Akkaya, M. Turabik, Biosorption of Acid Blue 290 (AB 290) and Acid Blue 324 (AB 324) dyes on Spirogyra rhizopus, J. Hazard. Mater. 135 (2006) 355364. https://doi.org/10.1016/j.jhazmat.2005.11.080.

[27] Y. Yang, X. Lin, B. Wei, Y. Zhao, J. Wang, Evaluation of adsorption potential of bamboo biochar for metal-complex dye: Equilibrium, kinetics and artificial neural network modeling, Int. J. Environ. Sci. Technol. 11 (2014) 1093-1100. https://doi.org/10.1007/s13762-013-0306-0.

[28] I. Langmuir, The adsorption of gases on plane surfaces of glass, mica and platinum, J. Am. Chem. Soc. 40 (1918) 1361-1403. https://doi.org/doi: 10.1021/ja02242a004.

[29] H.M.F. Freundlich, Over the adsorption in solution, J. Phys. Chem. 57 (1906) 358471.

[30] R. Sips, On the structure of a catalyst surface, J. Phys. Chem. 16 (1948) 490-495. https://doi.org/10.1063/1.1746922.

[31] O. Redlich, D.L. Peterson, A useful adsorption isotherm, J. Phys. Chem. 63 (1959) 1024.

[32] G.L. Dotto, N.P.G. Salau, J.S. Piccin, T.R.S.C. Jr., L.A.A. de Pinto, Adsorption Kinetics in Liquid Phase: Modeling for Discontinuous and Continuous Systems, in: A. Bonilla-Petriciolet, D.I. Mendoza-Castillo, H.E. Reynel-Ávila (Eds.), Adsorpt. 
587

588

589

590

591

592

593

594

595

596

597

598

599

600

601

602

603

604

605

606

607

608

609

610

611

Process. Water Treat. Purif., Springer Nature, 2017.

[33] S.K. Milonjić, A consideration of the correct calculation of thermodynamic parameters of adsorption, J. Serb. Chem. Soc. 72 (2007) 1363-1367.

https://doi.org/10.2298/JSC0712363M.

[34] J.S. Piccin, T.R.S.C. Jr., L.A.A. de Pinto, G.L. Dotto, Adsorption Isotherms in Liquid Phase: Experimental, Modeling, and Interpretations, in: A. Bonilla-Petriciolet, D.I. Mendoza-Castillo, H.E. Reynel-Avila (Eds.), Adsorpt. Process. Water Treat., 2017: pp. 19-51.

[35] D.C. Henrique, D. Uchoa Quintela, A. Honjo Ide, A. Erto, J.L. da Silva Duarte, L. Meili, Calcined Mytella falcata shells as alternative adsorbent for efficient removal of rifampicin antibiotic from aqueous solutions, J. Environ. Chem. Eng. (2020) 103782. https://doi.org/10.1016/j.jece.2020.103782.

[36] L.L.A. Melo, A.H. Ide, J.L.S. Duarte, C.L.P.S. Zanta, L.M.T.M. Oliveira, W.R.O. Pimentel, L. Meili, Caffeine removal using Elaeis guineensis activated carbon: adsorption and RSM studies, Environ. Sci. Pollut. Res. 27 (2020) 27048-27060. https://doi.org/10.1007/s11356-020-09053-z.

[37] K.H. Kim, J.Y. Kim, T.S. Cho, J.W. Choi, Influence of pyrolysis temperature on physicochemical properties of biochar obtained from the fast pyrolysis of pitch pine (Pinus rigida), Bioresour. Technol. 118 (2012) 158-162. https://doi.org/10.1016/j.biortech.2012.04.094.

[38] N. Iberahim, S. Sethupathi, M.J.K. Bashir, Optimization of palm oil mill sludge biochar preparation for sulfur dioxide removal, Environ. Sci. Pollut. Res. 25 (2018) 25702-25714.

[39] T. M. Almeida, M. D. Bispo, A. R. T. Cardoso, M. V. Migliorini, T. Schena, M. Cecilia V. de Campos, M. Elisabete Machado, J. A. López, L. C. Krause, E. B. 
612

613

614

615

616

617

618

619

620

621

622

623

624

625

626

627

628

629

630

631

632

633

634

635

636

Caramão, Preliminary Studies of Bio-oil from Fast Pyrolysis of Coconut Fibers, J. Agric. Food Chem. 61 (2013) 6812-6821. https://doi.org/10.1021/jf401379s.

[40] W.T. Tsai, M.K. Lee, Y.M. Chang, Fast pyrolysis of rice straw, sugarcane bagasse and coconut shell in an induction-heating reactor, (2006). https://doi.org/10.1016/j.jaap.2005.11.007.

[41] A. V Bridgwater, Review of fast pyrolysis of biomass and product upgrading, (2011). https://doi.org/10.1016/j.biombioe.2011.01.048.

[42] H.B. Goyal, D. Seal, R.C. Saxena, Renewable and Sustainable Energy Reviews 12 (2008) 504-517 Bio-fuels from thermochemical conversion of renewable resources: A review, (n.d.). https://doi.org/10.1016/j.rser.2006.07.014.

[43] N. Kumar Nayan, S. Kumar, R. Singh, Production of the liquid fuel by thermal pyrolysis of neem seed, (2012). https://doi.org/10.1016/j.fuel.2012.08.058.

[44] M. Thommes, K. Kaneko, A. V. Neimark, J.P. Olivier, F. Rodriguez-Reinoso, J. Rouquerol, K.S.W. Sing, Physisorption of gases, with special reference to the evaluation of surface area and pore size distribution (IUPAC Technical Report), Pure Appl. Chem. 87 (2015) 1051-1069.

[45] F. Pendolino, Self-assembly of molecules on nanostructured graphene, UNIVERSIDAD AUTÓNOMA DE MADRID, 2014.

[46] M. Ahmedna, W.E. Marshall, R.M. Rao, Surface properties of granular activated carbons from agricultural by-products and their effects on raw sugar decolorization, Bioresour. Technol. 71 (2000) 103-112. https://doi.org/10.1016/S09608524(99)90069-X.

[47] A.A. de A. Alves, G.L. de O. Ruiz, T.C.M. Nonato, L.C. Müller, M.L. Sens, Performance of the fixed-bed of granular activated carbon for the removal of pesticides from water supply, Environ. Technol. (United Kingdom). 40 (2019) 1977-1987. 
637

638

639

640

641

642

643

644

645

646

647

648

649

650

651

652

653

654

655

656

657

658

659

660

661

https://doi.org/10.1080/09593330.2018.1435731.

[48] K.Y. Foo, B.H. Hameed, Potential of jackfruit peel as precursor for activated carbon prepared by microwave induced $\mathrm{NaOH}$ activation, Bioresour. Technol. 112 (2012) 143-150. https://doi.org/10.1016/j.biortech.2012.01.178.

[49] C.I.A. Ferreira, V. Calisto, M. Otero, H. Nadais, V.I. Esteves, Comparative adsorption evaluation of biochars from paper mill sludge with commercial activated carbon for the removal of fish anesthetics from water in Recirculating Aquaculture Systems, Aquac. Eng. (2016). https://doi.org/10.1016/j.aquaeng.2016.06.003.

[50] R.M. Paixão, I.M. Reck, R. Bergamasco, M.F. Vieira, A.M.S. Vieira, Activated carbon of Babassu coconut impregnated with copper nanoparticles by green synthesis for the removal of nitrate in aqueous solution, Environ. Technol. (United Kingdom). 39 (2018) 1994-2003. https://doi.org/10.1080/09593330.2017.1345990.

[51] X. Liu, G. Yu, W. Han, Granular activated carbon adsorption and microwave regeneration for the treatment of 2,4,5-trichlorobiphenyl in simulated soil-washing solution, 147 (2007) 746-751. https://doi.org/10.1016/j.jhazmat.2007.01.076.

[52] U. Kalapathy, A. Proctor, J. Shultz, An improved method for production of silica from rice hull ash, Bioresour. Technol. 85 (2002) 285-289. https://doi.org/10.1016/S09608524(02)00116-5.

[53] Y. Xiao, H. Chen, M. Zheng, H. Dong, B. Lei, Y. Liu, Porous carbon with ultrahigh specific surface area derived from biomass rice hull, Mater. Lett. 116 (2014) 185-187. https://doi.org/10.1016/J.MATLET.2013.11.007.

[54] H. Sayłili, F. Güzel, Y. Önal, Conversion of grape industrial processing waste to activated carbon sorbent and its performance in cationic and anionic dyes adsorption, J. Clean. Prod. 93 (2015) 84-93. https://doi.org/10.1016/J.JCLEPRO.2015.01.009.

[55] Y. Shen, Y. Fu, KOH-activated rice husk char via $\mathrm{CO} 2$ pyrolysis for phenol adsorption, 
662

663

664

665

666

667

668

669

670

671

672

673

674

675

676

677

678

679

680

681

682

683

684

685

686

Mater. Today Energy. 9 (2018) 397-405.

https://doi.org/10.1016/j.mtener.2018.07.005.

[56] S.W. Nam, D.J. Choi, S.K. Kim, N. Her, K.D. Zoh, Adsorption characteristics of selected hydrophilic and hydrophobic micropollutants in water using activated carbon, J. Hazard. Mater. 270 (2014) 144-152. https://doi.org/10.1016/J.JHAZMAT.2014.01.037.

[57] B.Y.Z. Hiew, L.Y. Lee, X.J. Lee, S. Gan, S. Thangalazhy-Gopakumar, S.S. Lim, G.T. Pan, T.C.K. Yang, Adsorptive removal of diclofenac by graphene oxide: Optimization, equilibrium, kinetic and thermodynamic studies, J. Taiwan Inst. Chem. Eng. 98 (2019) 150-162. https://doi.org/10.1016/j.jtice.2018.07.034.

[58] M. El Haddad, A. Regti, R. Slimani, S. Lazar, Assessment of the biosorption kinetic and thermodynamic for the removal of safranin dye from aqueous solutions using calcined mussel shells, J. Ind. Eng. Chem. 20 (2014) 717-724. https://doi.org/10.1016/j.jiec.2013.05.038.

[59] J. Georgin, D.S.P. Franco, P. Grassi, D. Tonato, D.G.A. Piccilli, L. Meili, G.L. Dotto, Potential of Cedrella fissilis bark as an adsorbent for the removal of red 97 dye from aqueous effluents, Environ. Sci. Pollut. Res. (2019). https://doi.org/10.1007/s11356019-05321-9.

[60] G. Khan, M. Saood Manzar, P. Vanessa dos Santos Lins, M. Zubair, S. Ullah Khan, R. Selvasembian, L. Meili, N.I. Blaisi, M. Nawaz, H. Abdul Aziz, T.S. Kayed, RSMCCD optimization approach for the adsorptive removal of Eriochrome Black T from aqueous system using steel slag-based adsorbent: Characterization, Isotherm, Kinetic modeling and Thermodynamic analysis, J. Mol. Liq. (2021) 116714. https://doi.org/10.1016/j.molliq.2021.116714.

[61] L. Meili, P. V. Lins, C.L.P.S. Zanta, J.I. Soletti, L.M.O. Ribeiro, C.B. Dornelas, T.L. 
687

688

689

690

691

692

693

694

695

696

697

698

699

700

701

702

703

704

705

706

707

708

709

710

711

Silva, M.G.A. Vieira, MgAl-LDH/Biochar composites for methylene blue removal by adsorption, Appl. Clay Sci. 168 (2019) 11-20.

https://doi.org/10.1016/j.clay.2018.10.012.

[62] M.Y. Chang, R.S. Juang, Adsorption of tannic acid, humic acid, and dyes from water using the composite of chitosan and activated clay, J. Colloid Interface Sci. 278 (2004) 18-25. https://doi.org/10.1016/j.jcis.2004.05.029.

[63] X. Yang, B. Al-Duri, Kinetic modeling of liquid-phase adsorption of reactive dyes on activated carbon, J. Colloid Interface Sci. 287 (2005) 25-34.

https://doi.org/10.1016/j.jcis.2005.01.093.

[64] W. Wang, J. Wang, Comparative evaluation of sorption kinetics and isotherms of pyrene onto microplastics, Chemosphere. 193 (2018) 567-573.

https://doi.org/10.1016/j.chemosphere.2017.11.078.

[65] C.H. Giles, T.H. MacEwan, S.N. Nakhwa, D. Smith, Studies in adsorption part XI: a system of classification of solution adsorption isotherms, and its use in diagnosis of adsorption mechanisms and in measurement of specific surface areas of solids., J. Chem. Soc. 1 (1960) 3973-3993.

[66] J.L. Acero, F. Javier Benitez, F.J. Real, F. Teva, Coupling of adsorption, coagulation, and ultrafiltration processes for the removal of emerging contaminants in a secondary effluent, Chem. Eng. J. 210 (2012) 1-8. https://doi.org/10.1016/j.cej.2012.08.043.

[67] S. Álvarez, R.S. Ribeiro, H.T. Gomes, J.L. Sotelo, J. Garc??a, Synthesis of carbon xerogels and their application in adsorption studies of caffeine and diclofenac as emerging contaminants, Chem. Eng. Res. Des. 95 (2015) 229-238. https://doi.org/10.1016/j.cherd.2014.11.001.

[68] I. Anastopoulos, I. Pashalidis, The application of oxidized carbon derived from Luffa cylindrica for caffeine removal. Equilibrium, thermodynamic, kinetic and mechanistic 
analysis, J. Mol. Liq. 296 (2019) 112078. https://doi.org/10.1016/j.molliq.2019.112078.

[69] I. Anastopoulos, A. Katsouromalli, I. Pashalidis, Oxidized biochar obtained from pine needles as novel adsorbent to remove caffeine from aqueous solutions, J. Mol. Liq. 304 (2020) 112661. https://doi.org/10.1016/j.molliq.2020.112661.

[70] K.K. Beltrame, A.L. Cazetta, P.S.C. de Souza, L. Spessato, T.L. Silva, V.C. Almeida, Adsorption of caffeine on mesoporous activated carbon fibers prepared from pineapple plant leaves, Ecotoxicol. Environ. Saf. 147 (2018) 64-71. https://doi.org/10.1016/j.ecoenv.2017.08.034.

[71] Y.M. Correa-Navarro, L. Giraldo, J.C. Moreno-Piraján, Dataset for effect of $\mathrm{pH}$ on caffeine and diclofenac adsorption from aqueous solution onto fique bagasse biochars, Data Br. 25 (2019) 104111.

[72] S.A.C. Carabineiro, T. Thavorn-Amornsri, M.F.R. Pereira, J.L. Figueiredo, Adsorption of ciprofloxacin on surface-modified carbon materials, Water Res. 45 (2011) 45834591. https://doi.org/10.1016/j.watres.2011.06.008.

[73] J.L. Sotelo, A. Rodriguez, S. Alvarez, J. Garcia, Removal of caffeine and diclofenac on activated carbon in fixed bed column, Chem. Eng. Res. Des. 90 (2012) 967-974. https://doi.org/10.1016/j.cherd.2011.10.012.

[74] J.L. Sotelo, G. Ovejero, A. Rodríguez, S. Álvarez, J. García, Study of natural clay adsorbent sepiolite for the removal of caffeine from aqueous solutions: Batch and fixed-bed column operation, Water. Air. Soil Pollut. 224 (2013). https://doi.org/10.1007/s11270-013-1466-8.

[75] D.U. Quintela, D.C. Henrique, P.V. dos S. Lins, A.H. Ide, A. Erto, J.L. da S. Duarte, L. Meili, Waste of Mytella Falcata shells for removal of a triarylmethane biocide from water: Kinetic, equilibrium, regeneration and thermodynamic studies, Colloids 
Surfaces B Biointerfaces. 195 (2020).

738 https://doi.org/https://doi.org/10.1016/j.colsurfb.2020.111230.

739

740

741

742

743

744

745

746

[76] L. Wang, J. Li, Adsorption of C.I. Reactive Red 228 dye from aqueous solution by modified cellulose from flax shive: Kinetics, equilibrium, and thermodynamics, Ind. Crops Prod. 42 (2013) 153-158. https://doi.org/10.1016/j.indcrop.2012.05.031.

[77] M.A. Khan, S. wook Kim, R.A.K. Rao, R.A.I. Abou-Shanab, A. Bhatnagar, H. Song, B.H. Jeon, Adsorption studies of Dichloromethane on some commercially available GACs: Effect of kinetics, thermodynamics and competitive ions, J. Hazard. Mater. 178 (2010) 963-972. https://doi.org/10.1016/j.jhazmat.2010.02.032. 